\title{
Mechanism and role of nitric oxide signaling in periodontitis
}

\author{
YAN WANG ${ }^{1}$, XIANGDAO HUANG $^{1}$ and FUMING HE $^{2}$ \\ ${ }^{1}$ Department of Stomatology, The East Campus of Beihua University, Jilin, Jilin 132000; ${ }^{2}$ Department of Stomatology, \\ The Affiliated Dental Hospital of Zhejiang University School of Medicine, Hangzhou, Zhejiang 310006, P.R. China
}

Received July 18, 2018; Accepted April 5, 2019

DOI: $10.3892 /$ etm.2019.8044

\begin{abstract}
The present study investigated the role of the nitric oxide (NO) signaling pathway in the progression of periodontal disease, and explored the related genetic mechanisms. An experimental model of periodontitis was established in Sprague-Dawley rats, then they were divided into normal control, and 2, 4 and 6 weeks post-surgery groups. NO content was determined in the saliva of rats from each group by the Griess reagent method. Pathological changes of the periodontal tissue sections were evaluated with hematoxylin-eosin staining. The periodontal tissue sections were also evaluated by immunohistochemistry to detect the expression of inducible nitric oxide synthase 2 (iNOS2). Significant differences were detected in the iNOS2 expression of the periodontal tissue based on immunohistochemistry. There was a significant time-dependent increase in NO serum levels post-surgery. Two single nucleotide polymorphisms (SNP), rs2297518 in the iNOS gene and rs841 of the GTP cyclohydrolase I gene, were identified to be closely related to alveolar bone resorption, which is associated with the SNP rs1049255 of the cytochrome b-245 $\alpha$ chain gene. The present findings demonstrated that iNOS2 values increased and NO levels increased with the progression of periodontitis. These results are in agreement with the previous literature. It was hypothesized that NO has a role in the occurrence and development of periodontal disease by regulating the action of certain cytokines.
\end{abstract}

\section{Introduction}

Microorganisms and toxic factors are the predominant causative agents of periodontitis. In response to activated tissues, macrophages and lymphocytes produce matrix metalloproteinases and inflammatory factors, such as interleukin-1 (IL-1) and tumor necrosis factor (TNF) (1), which serve essential roles in periodontal tissue destruction. Therefore, many inflammatory

Correspondence to: Dr Yan Wang, Department of Stomatology, The East Campus of Beihua University, 3999 Huashan Road, Fengman, Jilin, Jilin 132000, P.R. China

E-mail: yanwang5434664@sina.com

Key words: periodontal disease, nitric oxide, inducible nitric oxide synthase 2 , cytochrome b-245 $\alpha$ chain mediators are considered to be crucial in the development of early periodontal disease with nitric oxide (NO) the main inflammatory factor in this disease (2).

NO is an extremely unstable, fat-soluble gas at room temperature that can diffuse rapidly through biofilms. NO is mainly generated by the catalysis of nitric oxide synthase (NOS) in an organism, for example by the enzyme inducible nitric oxide synthase (iNOS). iNOS expression and production levels are markedly increased following injury when cells are activated by external stimuli (3). Therefore, the present study hypothesized that iNOS likely participates in the development of periodontal disease (4). In 1993, Bodis and Haregewoin (5) identified the presence of NO in saliva, thereby providing the groundwork for the study of NO in oral medicine and biology.

NO mediates the pathological effects of lipopolysaccharide (LPS), TNF, IL-1, and other cytokines, regulates leukocyte and epithelial cell adhesion, inhibits $\mathrm{T}$ cell proliferation, and improves natural killer (NK) cell activity, amongst other immune-related processes. These findings demonstrated that NO is closely related to immune function. Given the association of LPS, TNF, and IL-1 in the development of periodontal disease, it was hypothesized that NO may be involved in the progression of periodontal disease by regulating the action of these and other cytokines (6).

To test this hypothesis, the present study established an experimental periodontitis model in Sprague-Dawley (SD) rats then examined the clinical manifestations and pathological changes of periodontitis at different time periods, and detected the expression of NO in the periodontium and serum. The present findings provided a foundation for clarifying the role of the NO signaling pathway in periodontitis development and its mechanism of action.

\section{Materials and methods}

Establishment of the experimental animal model and grouping. Forty-eight SD male rats $(201.79 \pm 17.86$ g; 9 weeks old) bought from Shanghai Slaccas were used in this study. All animal experiments were approved by the Laboratory Animal Center of Beihua University. The rats were randomly divided into the four groups $(n=12)$ : Normal control group, 2 weeks post-operation, 4 weeks post-operation and 6 weeks post-operation. All the rats had free access to water, and maintained under constant environmental conditions with temperature of $25^{\circ} \mathrm{C}, 50 \%$ humidity, noise $<85$ decibels, ventilation once every $12 \mathrm{~h}$, and a 12-h light/dark cycle. 
To establish the periodontal disease model, the rats were routinely fed for one week, and then maxillary first molar ligation was performed. The animals were monitored for signs of peritonitis. In brief, rats were anesthetized with $10 \%$ chloral hydrate $(300 \mathrm{mg} / \mathrm{kg})$. Rats were placed in the supine position and fixed on the operating table, then the bilateral maxillary first molars were ligated by simple ligation. The first maxillary molars were wrapped by $0.2 \mathrm{~mm}$ orthodontic ligation, and the filaments were placed as far as possible on the bottom of the gingival sulcus, with the ligation tied to the palate. Each rat was labeled clearly. All procedures were approved by the Animal Care and Use Committee of The Beihua University and conformed to the guidelines of the National Institute of Health.

Specimen collection. Following the operation at 2, 4 and 6 weeks, saliva, abdominal aorta blood, and periodontal tissue samples were collected under anesthesia. Salivation was induced by subcutaneous administration of $10 \mathrm{mg} / \mathrm{kg}$ pilocarpine (Sigma-Aldrich; Merck KGaA) in PBS. Saliva was collected with a pipette over a 15 min period then transferred to a microcentrifuge tube containing protease inhibitor (Complete Mini; Roche Diagnostics). Saliva was then vortexed for $1 \mathrm{~min}$, centrifuged at $16,000 \mathrm{x}$ g for $5 \mathrm{~min}$ at $4^{\circ} \mathrm{C}$ and transferred to a new tube, leaving behind any precipitated debris from the mouth. This protocol ensures that intact microorganisms present in the collected saliva are excluded from being processed with the salivary proteins.

Determination of $\mathrm{NO}$ in the saliva by the Griess method. Saliva was collected and stored at $-20^{\circ} \mathrm{C}$. When fully thawed, the saliva was tested for NO content using the Nitric Oxide (Enzymatic) kit (cat. no. ab65328; Abcam) instructions. The optical density (OD) values of the measurement and standard tubes were measured at $530 \mathrm{~nm}$ in a $0.5-\mathrm{cm}$ cuvette, using a blank tube standardized as zero. An average value was taken as the final reading. NO content in each serum sample was calculated by the following formula: NO content $(\mu \mathrm{mol} / \mathrm{l})=($ sample OD value-blank OD value)/(standard OD value-blank OD value) $\mathrm{x}$ standard concentration $(100 \mu \mathrm{mol} / \mathrm{l})$.

Collection and treatment of serum specimens. Anesthetized rats were injected intraperitoneally with $10 \%$ chloral hydrate $(300 \mathrm{mg} / \mathrm{kg})$. All the animals were monitored for any signs of peritonitis. Three rats in the control group and all rats in the other groups were selected at 2,4, and 6 weeks after the operation for blood collection. Abdominal aorta blood was extracted with a single sterile needle head, and the blood was centrifuged for $10 \mathrm{~min}\left(4^{\circ} \mathrm{C} ; 3,800 \mathrm{x} \mathrm{g}\right)$. The supernatant was collected and stored at $-20^{\circ} \mathrm{C}$ until experimentation.

Extraction and treatment of tissue specimens. Following blood collection, the rats were sacrificed, and the bilateral maxillary bones containing the first molar, the surrounding gingiva, and alveolar bone tissue were dissected. The periodontal tissue specimens were fixed in $4 \%$ paraformaldehyde solution for $16 \mathrm{~h}$, at $4^{\circ} \mathrm{C}$ and then decalcified in $10 \%$ solution of $\mathrm{pH}$ 7.2-7.3. The solution was replaced every two days until a pin could pass through the tissue without resistance. The tissue was then trimmed, dehydrated, immersed in wax, and embedded in paraffin. A series of tissue sections with thickness of $4 \mu \mathrm{m}$ were made from the paraffin blocks of each specimen. The pathological lesions were reported by an animal pathologist.

Hematoxylin-eosin (HE) staining. Histopathological sections of rats in each group were stained with HE to observe the pathological changes of periodontal tissues in each group. A light microscope was used to observe the slices.

Expression of $\mathrm{NO}$ in the periodontal tissues of rats with periodontitis by immunohistochemistry. Histopathological sections were stained with rabbit anti-iNOS2 $(1: 1,000$; cat. no. ab15323; Abcam) at $4^{\circ} \mathrm{C}$ overnight using the streptavidin-biotin complex method for periodontal tissue. Samples were incubated with secondary antibody peroxidase-labeled streptavidin-biotin complex (1:1,000; Dako; cat. no. P0447; Agilent Technologies, Inc.) for $30 \mathrm{~min}$ at $37^{\circ} \mathrm{C}$. Subsequently, the samples were observed using a fluorescence microscope at x20 magnification (Olympus Bio-fluorescence Microscope BX53; Olympus Corporation). A total of three optical fields were viewed per section. A total of 12 sections were analyzed per sample and per group. Then the value was calculated by Image J software (National Institute of Health).

Expression of $\mathrm{NO}$ in the serum of rats with periodontitis by the nitrate reduction method. The expression of NO in the serum of rats with periodontitis was determined through nitrate reduction, as $\mathrm{NO}$ is quickly transformed into nitrate $\left(\mathrm{NO}_{3}\right)$ and nitrite $\left(\mathrm{NO}_{2-}\right)$ in vivo. In brief, a $\mathrm{NO}$ reduction kit (Nanjing Institute of Bioengineering) was used to measure the concentration of NO based on the color intensity, according to the manufacturer's protocol. The mixed reagent, chromogenic agent, and $100 \mu \mathrm{mol} / 1$ standard application solution were prepared for NO detection.

In brief, the serum supernatant and chromogenic agent were mixed well, left at room temperature for $10 \mathrm{~min}$, and then the absorbance was determined at $550 \mathrm{~nm}$ and compared with the standard of double-steamed water (OD adjusted to zero). The NO content in each serum sample was calculated by the following formula: NO content $(\mu \mathrm{mol} / \mathrm{l})=($ sample OD value-blank $\mathrm{OD}$ value)/(standard OD value-blank OD value) $\mathrm{x}$ standard concentration $(100 \mu \mathrm{mol} / \mathrm{l})$. The experiments were repeated three times.

Gene chip technology to detect genes associated with the NO signaling pathway in the course of periodontitis. Selected tissue samples of periodontitis rats were stored in liquid nitrogen and were detected using an NO signaling gene chip that was obtained from Shanghai Kangcheng Bioengineering Co., Ltd. This contained 113 genes associated with NO signaling pathway. Furthermore, the chip contained target genes downstream of the NO signaling pathway, which were involved in the biosynthesis of NO, hyperoxidative metabolism and oxidative stress processes, and genes that were promoted or suppressed by NO. These genes were indicatives of whether the NO signaling pathway was activated.

Samples $(50 \mathrm{mg}$ ) were immersed in $0.5 \mathrm{ml} \mathrm{TRIzol} \mathrm{solu-}$ tion (Invitrogen; Thermo Fisher Scientific, Inc.), and the supernatant of the tissue suspension was centrifuged at $4,900 \times \mathrm{g}$. The supernatant was discarded, the genomic RNA 
extracted and the sample was transferred to a sterile $1.5-\mathrm{ml}$ tube. Chloroform/isoamyl alcohol (24:1; total $200 \mathrm{ml})$ was added, and the solution was shaken vigorously for $30 \mathrm{sec}$. The supernatant was carefully transferred to an RNase free $1.5-\mathrm{ml}$ tube and centrifuged at $10,8000 \mathrm{x} \mathrm{g}$ at room temperature for 5 min. The supernatant was carefully removed to obtain tissue RNA. Sample concentration $(\mu \mathrm{g} / \mathrm{ml})$ was determined by the following formula: A260x40x500 dilution factor.

The labeling of cRNA and the purification of synthetic cRNA were determined according to the True Labeling-AMP/linear RNA amplification kit and the SuperArray ArrayGrade cRNA purification kit specification. The SuperArray ArrayGrade cRNA purification kit instructions were used for the operation. Sample concentration $(\mu \mathrm{g} / \mathrm{ml})=\mathrm{A} 260 \times 40 \times 500$ (dilution multiple). The ratio of OD260/280 to OD260/230 was calculated to determine the purity of the sample.

The expression level of NO-related genes in experimental periodontitis tissues of rats can be detected simultaneously using the nucleic acid hybridization technique, and the key genes of NO signaling pathway in the course of periodontitis can be screened (7). The attachment loss was measured using radiographic measurements (Ysio; Siemens Healthineers) and standardized with the Bioquant software (Shanghai AB SCIEX Analytical Instrument Trading Co.) based on the tooth width which was measured with a caliper.

Statistical analysis. All data were analyzed using SPSS v.20.0 software (IBM Corp.) and expressed as the mean \pm standard deviation. Student's t-test was used to compare the difference between two groups. One-way analysis of variance followed by Bonferroni post hoc test was used for multiple comparison tests. Significant differences were further evaluated between groups using the least significant difference test. $\mathrm{P}<0.05$ was considered to indicate statistical significance.

\section{Results}

Rat periodontal tissue clinical changes following establishment of periodontitis model. Before the operation, rats displayed healthy periodontal tissue with pink gums (Fig. 1A). Surgery with ligation of the first molar and palatal fixation, and food residue and soft scales are presented in Fig. 1B and C, respectively. Two weeks post-surgery, gingival edema and a small amount of bleeding were observed (Fig. 1D). Four weeks post-surgery, red gingival tissue with an irregular edge was present with bleeding easily induced (Fig. 1E). Six weeks post-surgery, dull-red atrophied gingival tissue was observed with bleeding easily induced (Fig. 1F).

Saliva NO content increases with periodontitis progression. A time-dependent significant increase in saliva NO content was detected with progression of periodontitis (Fig. 2).

Tissue health declines with periodontitis progression. Histopathological changes of periodontal tissue were evaluated by HE staining. The normal control group demonstrated a non-keratinized squamous epithelium, no epithelial spikes, an intact smooth surface of the alveolar bone, and no formation of osteocytes or lacunae (Fig. 3A). Tissue samples from 2 weeks post-operation demonstrated proliferation of epithelial rete
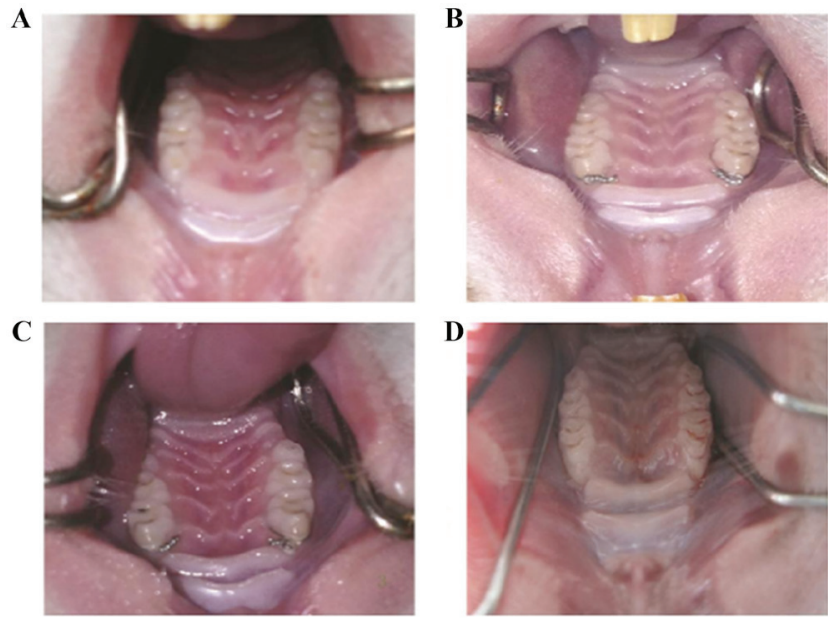

$\mathbf{E}$
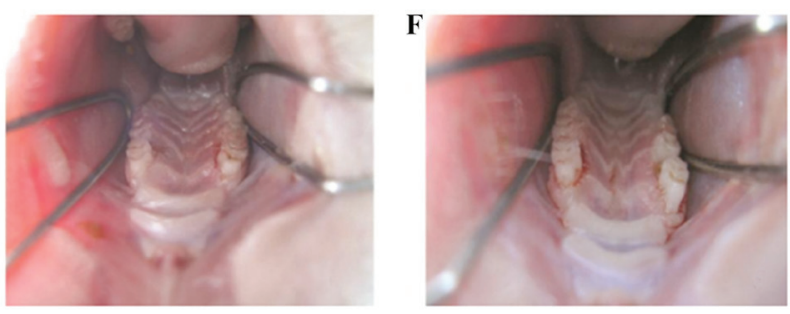

Figure 1. Oral condition of normal and experimental rats following periodontal surgery. (A) Healthy rats displayed no caries, healthy periodontal tissue, pink gums, tensile texture and no bleeding. (B) Surgery with ligation of the first molar and palatal fixation. (C) Food residue and soft scales. (D) Two weeks post-surgery with rats demonstrating gingival edema and a small amount of bleeding. (E) Four weeks post-surgery with rats demonstrating red gingival with an irregular edge and bleeding. (F) Six weeks post-surgery with rats demonstrating dull-red gingival, atrophy and bleeding.

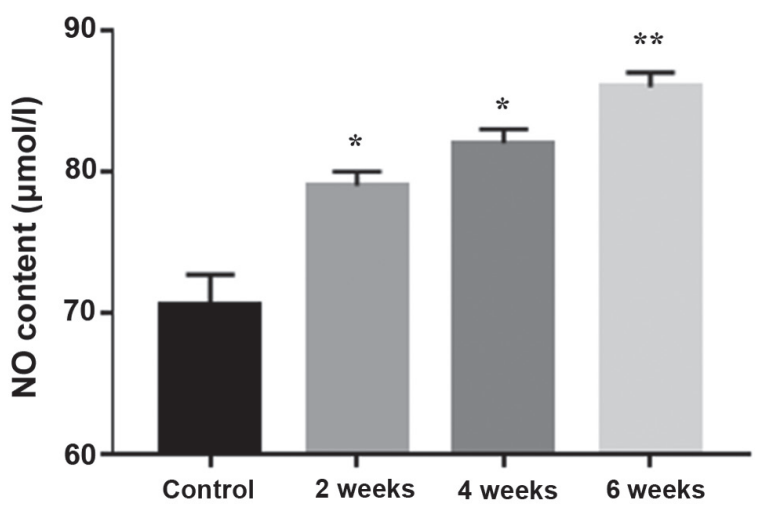

Figure 2. NO content in the saliva of each group determined by the Griess method. ${ }^{*} \mathrm{P}<0.05,{ }^{* *} \mathrm{P}<0.01$ vs. Control. $\mathrm{NO}$, nitric oxide.

pegs, invasion of the connective tissue into the lower part, edema of the connective tissue, infiltration of lymphocytes and neutrophils, and intact alveolar bone (Fig. 3B). Tissue samples from 4 weeks post-operation demonstrated disordered collagen fibers, edema, tissue degeneration and loss, with a large number of infiltrated inflammatory cells (primarily neutrophilic granulocytes), combined with epithelium proliferation, and a large number of lymphocytes in the connective tissue of the subepithelial tissue. Alveolar bone exhibited a few active osteoclastic resorption lacuna with alveolar ridge top and destruction of the inherent alveolar bone resorption (Fig. 3C). 

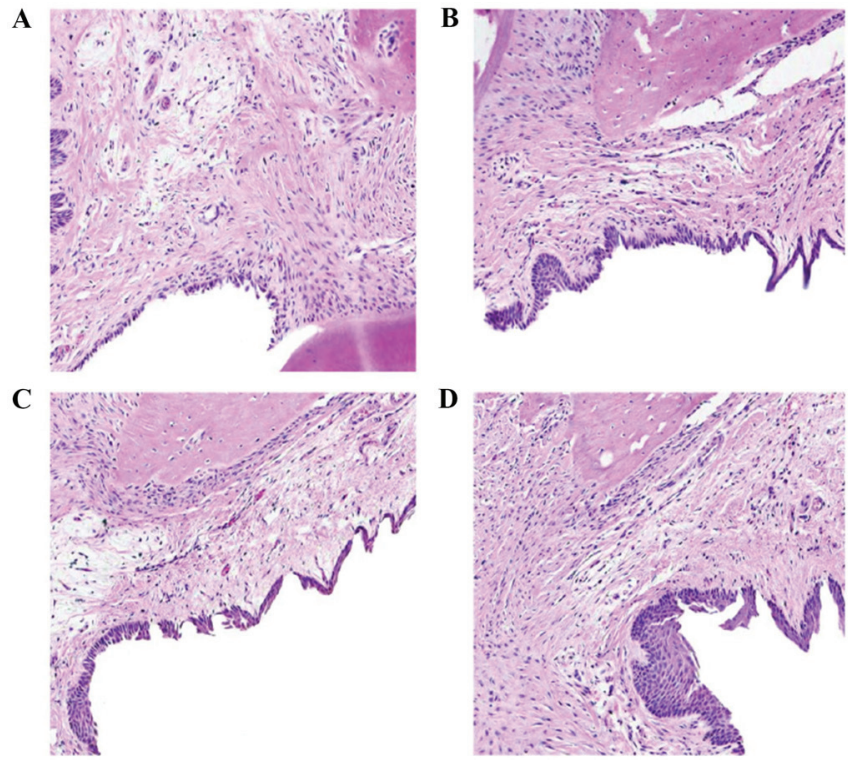

Figure 3. Hematoxylin-eosin staining of periodontal tissues. (A) Normal control group. (B) Tissue from 2 weeks post-operation. (C) Tissue from 4 weeks post-operation. (D) Tissue from 6 weeks post-operation (magnification, x10).

Tissue samples from 6 weeks post-operation demonstrated dissolved subepithelial connective tissue, denatured collagen fibers and prolific inflammatory cell infiltration into the alveolar bone. The alveolar crest was also destroyed and vertical absorption was observed (Fig. 3D). Representative examples of these histopathological changes are also demonstrated at higher magnification in Fig. 4.

iNOS2 levels increase with periodontitis progression. Tissue sections of the rats of each group were analyzed to observe the expression of iNOS2 (brown staining) in the periodontal tissue (Fig. 5). iNOS2 expression levels varied significantly between groups $(\mathrm{P}<0.001$; Table I).

Serum NO expression and attachment loss increases with periodontitis progression. NO contents in the serum significantly increased with disease progression $(\mathrm{P}<0.001$; Fig. 6A). There was a significant difference in $\mathrm{NO}_{2}-/ \mathrm{NO}_{3}$ - levels $(\mathrm{P}<0.05)$ between the periodontitis and the normal control group in the gingival tissue at 2 weeks post-operation. By contrast, 4 and 6 weeks post-operation, the $\mathrm{NO}_{2}-/ \mathrm{NO}_{3}$ - levels were significantly higher compared with the normal control group $(\mathrm{P}<0.001$; Fig. 6A). Similar results were observed for attachment loss with increasing attachment loss during the progression of periodontitis (Fig. 6B).

\section{Discussion}

The histopathological changes of human periodontitis can be adequately replicated in an animal model using local periodontal stimuli such as silk thread to knot the teeth and neck of the animal (8). In the present study, clinical observation of the periodontal changes and the pathological examination of periodontal tissues demonstrated that a rat model of periodontitis was successfully established using the ligature method.
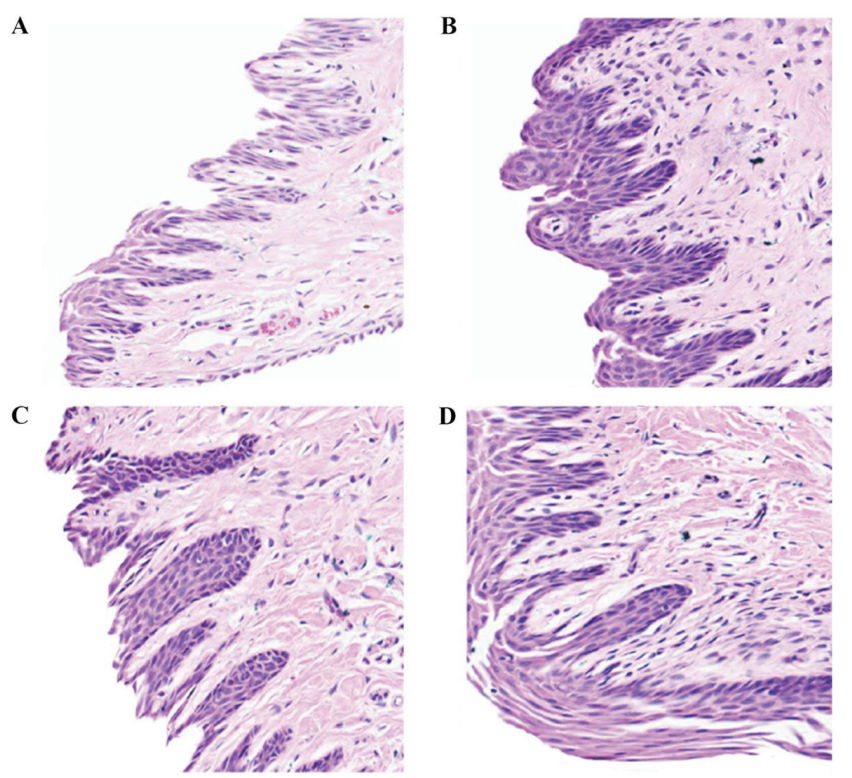

Figure 4. Hematoxylin-eosin staining of periodontal tissues. (A) Normal control group. (B) Tissue from 2 weeks post-operation. (C) Tissue from 4 weeks post-operation. (D) Tissue from 6 weeks post-operation (magnification, x20).

Immunohistochemical staining can be used to evaluate the intensity of iNOS expression in periodontal tissues (9). It has been hypothesized that iNOS levels increase in patients with periodontitis, depending on the severity of inflammation. Macrophages demonstrate the greatest expression of iNOS amongst cells (10). A recent study determined that NO dilates blood vessels in the rabbit aorta (11). The increased level of $\mathrm{NO}$ in patients with periodontitis is attributed to the increased levels of iNOS expression in periodontal tissue cells during inflammation (12). An increase in NO content leads to vascular permeability and swelling of the gums leading to the gingival redness and swelling characteristic of periodontitis [14]. During periodontal probing, an increase in the bleeding index of the gums may be caused by inhibition of platelet aggregation and adhesion mediated by increased NO production. By contrast, the decrease in alveolar bone height and increase in absorption is likely caused by the increased osteoclast activity induced by NO stimulation (12).

The present study determined that there was an increased expression of iNOS2 in the gingival blood vessels, which may be related to the vasodilation effect of NO. Moreover, iNOS2 is abundantly produced by inflammatory cells such as macrophages (13), with the concentration determined by the extent of inflamed tissues, and bacterial stimulation. The present immunohistochemical results supported the hypothesis that iNOS2 expression in periodontal tissues increased during the development of periodontitis (14).

Menaka et al (15), determined that $\mathrm{NO}_{3}$ and $\mathrm{NO}_{2-}$ in the serum is due to synthesis of NO by NOS from L-arginine, and also from ingested food. Serum $\mathrm{NO}_{2-}$ and $\mathrm{NO}_{3-}$ are mainly derived from the L-arginine/NO pathway following fasting for $12 \mathrm{~h}$. Moshage et al (16) identified that NO content can be fully determined from measurement of $\mathrm{NO}_{2-}$ and $\mathrm{NO}_{3-}$ in the serum after a blood sample is left to solidify at room temperature for 30 min. Concentrations of serum $\mathrm{NO}_{2}$ has been demonstrated to significantly increase in patients with periodontitis compared 
Table I. NO expression levels in the periodontal tissue of different groups.

\begin{tabular}{lcccr}
\hline Comparison & Sum of squares & df & Mean square & F-test \\
\hline Between groups & $1,523.43$ & 3 & 507.820 & 101.824 \\
Within groups & 159.58 & 32 & 4.986 & 9.714 \\
\hline
\end{tabular}

A

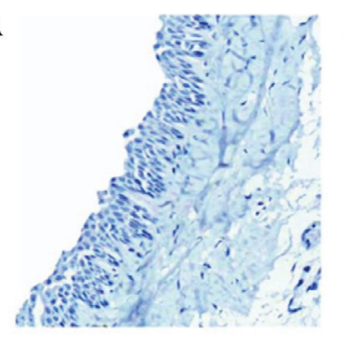

B
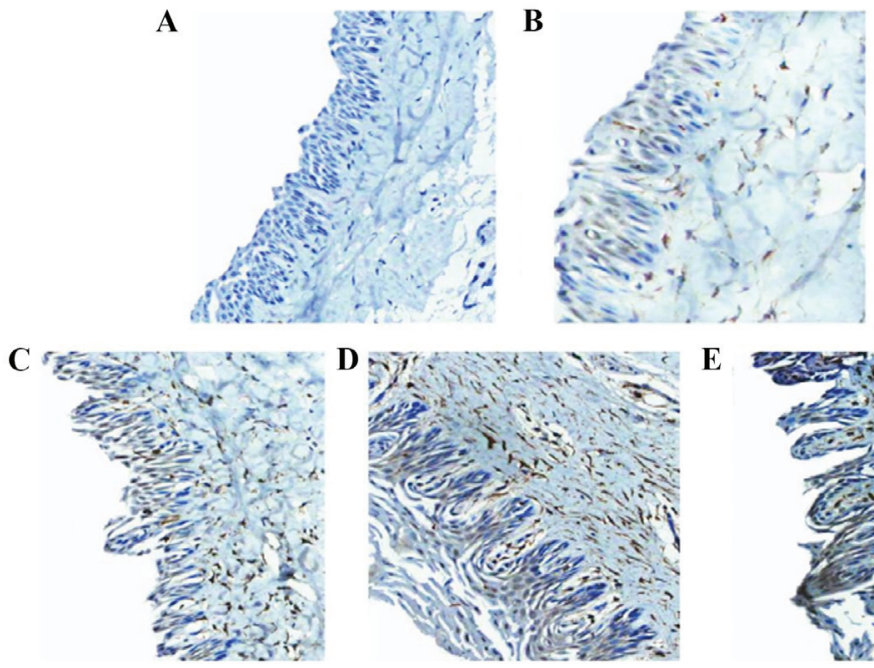

E

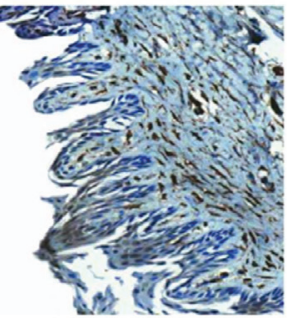

Figure 5. Inducible nitric oxide synthase 2 expression in periodontal tissues. (A) Blank control with primary antibody only and PBS instead of secondary antibody. (B) Normal control group. (C) Tissue from 2 weeks post-operation. (D) Tissue from 4 weeks post-operation. (E) Tissue from 6 weeks post-operation (magnification, $\mathrm{x} 20$ ).
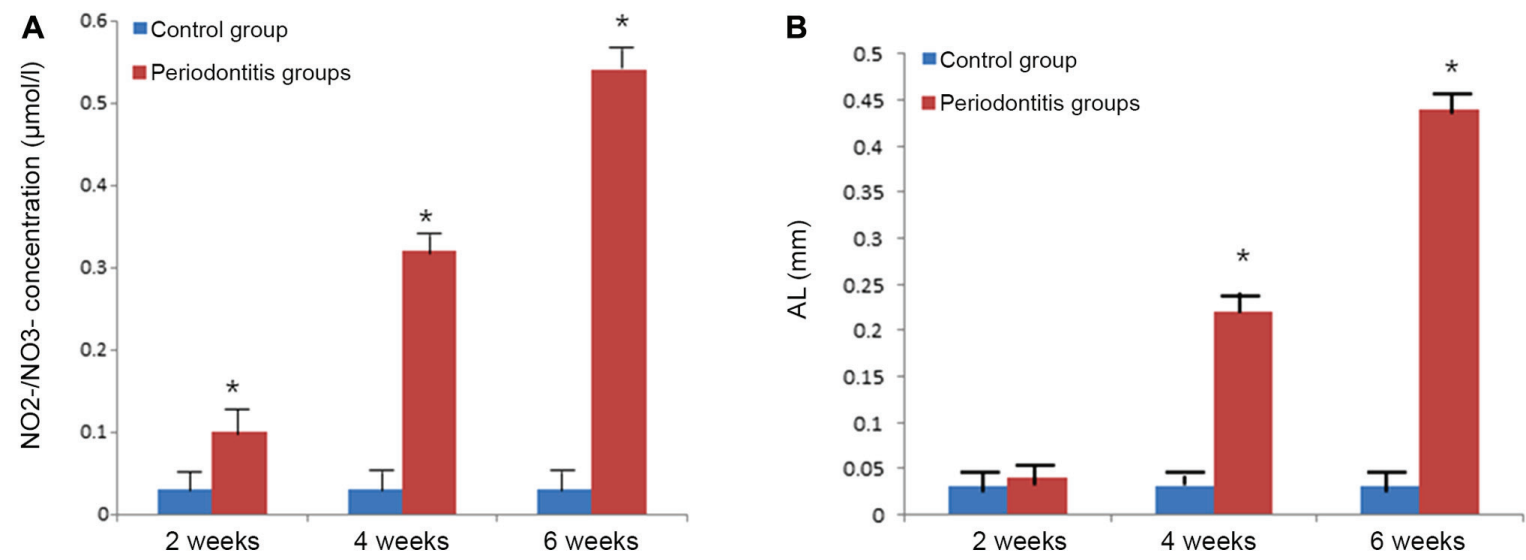

Figure 6. $\mathrm{NO}_{2}{ }^{-}$and $\mathrm{NO}_{3}{ }^{-}$expression levels in serum and clinical $\mathrm{AL}$ analysis. (A) $\mathrm{NO}_{2}{ }^{-}$and $\mathrm{NO}_{3}{ }^{-}$expression in control, and 2, 4 and 6 week periodontitis groups . (B) Clinical $\mathrm{AL}$ for the control, and 2, 4 and 6 week periodontitis groups. ${ }^{*} \mathrm{P}<0.05$ vs. control. $\mathrm{NO}_{2}{ }^{-}$, nitrite; $\mathrm{NO}_{3}{ }^{-}$, nitrate; $\mathrm{AL}$, attachment loss .

with healthy controls, with a significant increase in NO levels reported to contribute to the development of periodontitis (17). Wadhwa et al (18) demonstrated that NO levels in the serum and saliva are good indicators to evaluate the inflammatory status of periodontal tissues. It is also believed that smoking increases the extent of periodontal injury, and smokers also have a greater incidence of periodontal disease expressing higher NO serum and saliva NO levels than non-smokers (19). Increased salivary NO levels were associated with a greater severity of periodontitis (20), and non-smoking patients with periodontitis showed increased $\mathrm{NO}_{2}$ - levels compared with healthy patients (21). Hussain et al (22) measured the contents of $\mathrm{NO}_{2-}$ and $\mathrm{NO}_{3-}$ in the gingival tissue of rats and indirectly determined the content of NO in gingival tissue. Compared with the periodontitis group, the $\mathrm{NO}_{2-}$ and $\mathrm{NO}_{3}$. content in the periodontium gingival tissue was significantly increased, and increased with progression of periodontitis. Given that NO also displays anti-inflammatory effects (4), it likely acts bi-directionally where low concentrations inhibit inflammation whilst high concentrations aggravate the development of inflammation.

By contrast, one study demonstrated that the NO metabolite $\mathrm{NO}_{2}$ - content in the saliva of periodontitis patients was reduced compared with healthy subjects (23). Moreover, 
Andrukhov et al (24) determined that NO levels in saliva and serum reflected a decreasing trend compared with the normal control group. However, given that NO is clearly expressed in periodontal disease tissues and its content increases with disease progression, it evidently serves a role in the development of periodontal disease.

Based on the results of genetic analysis, it was hypothesized that NO and iNOS were involved in the progression of periodontal disease. SNP rs2297518 of the iNOS gene, SNP rs1049255 of the cytochrome b-245 $\alpha$ chain gene, and SNP rs841 of the GTP cyclohydrolase I are transcripted into mRNA, leading to expression of iNOS protein. L-arginine and iNOS protein combine in NO synthesis, which mediates the pathological effects of LPS (25). This in turn regulates leukocytes and epithelial cell adhesion, thereby inhibiting $\mathrm{T}$ cell proliferation to increase NK cell activity (26). In addition, bacterial virulence along with the immune cell response leads to tissue destruction, periodontitis, and ultimately alveolar bone absorption and destruction (27).

In conclusion, the present results determined that NO expression increases gradually with the progression of periodontitis by inducing the action of certain cytokines.

\section{Acknowledgements}

Not applicable.

\section{Funding}

No funding was received.

\section{Availability of data and materials}

The datasets generated and/or analyzed during the current study are available from the corresponding author on reasonable request.

\section{Authors' contributions}

YW and $\mathrm{XH}$ designed the study and interpreted results of experiments. $\mathrm{YW}, \mathrm{XH}$ and $\mathrm{FH}$ also contributed to the design of the study and the interpretation of experimental results. XH and FH performed experiments, analyzed data, prepared figures and drafted the manuscript. YW, XH and FH approved final version of manuscript. YW edited and revised manuscript.

\section{Ethics approval and consent to participate}

The animal study was approved by the Animal Care and Use Committee of The Beihua University and conformed with the guidelines of National Institute of Health.

\section{Patient consent for publication}

Not applicable.

\section{Competing interests}

The authors declare that they have no competing interests.

\section{References}

1. Vonholdt J, Gonzáles JR, Michel J, Herrmann JM and Meyle J: Interleukin-1 polymorphism in patients with early onset-and adult periodontitis. Int Poster J Dent Oral Med 3: 72, 2001.

2. Pacher P, Beckman JS and Liaudet L: Nitric oxide and peroxynitrite in health and disease. Physiol Rev 87: 315-424, 2007.

3. Reeves SR, Simakajornboon N and Gozal D: The role of nitric oxide in the neural control of breathing. Respir Physiol Neurobiol 164: 143-150, 2008.

4. Schmidt HH, Nau H, Wittfoht W, Gerlach J, Prescher KE, Klein MM, Niroomand F and Böhme E: Arginine is a physiological precursor of endothelium-derived nitric oxide. Eur J Pharmacol 154: 213-216, 1988.

5. Bodis S and Haregewoin A: Evidence for the release and possible neural regulation of nitric oxide in human saliva. Biochem Biophys Res Commun 194: 347-350, 1993.

6. Do MJ, Kim K, Lee H, Cha S, Seo T, Park HJ, Lee JS and Kim TI: Development of animal experimental periodontitis models. J Periodontal Implant Sci 43: 147-152, 2013.

7. Lockhart PB, Bolger AF, Papapanou PN, Osinbowale O, Trevisan M, Levison ME, Taubert KA, Newburger JW, Gornik HL, Gewitz MH, et al: Periodontal disease and atherosclerotic vascular disease: Does the evidence support an independent association? A scientific statement from the American heart association. circulation 125: 2520-2544, 2012.

8. Achong R, Nishimura I, Ramachandran H, Howell TH, Fiorellini JP and Karimbux NY: Membrane type (MT) 1-matrix metalloproteinase (MMP) and MMP-2 expression in ligature-induced periodontitis in the rat. J Periodontol 74: 494-500, 2003.

9. Albandar JM and Rams TE: Global epidemiology of periodontal diseases: An overview. Periodontol 2000 29: 7-10, 2002.

10. Lappin DF, Kjeldsen M, Sander L and Kinane DF: Inducible nitric oxide synthase expression in periodontitis. J Periodontal Res 35: 369-373, 2000.

11. Poorsattar Bejeh Mir A: Focusing on periodontitis as a vasculupathy: The therapeutic possibilities from the perspective of a dentistry student. J Pharm Biomed Sci 13, 2011.

12. López NJ, Smith PC and Gutierrez J: Higher risk of preterm birth and low birth weight in women with periodontal disease. J Dent Res 81: 58-63, 2002.

13. Teng YT: Protective and destructive immunity in the periodontium: Part 1-innate and humoral immunity and the periodontium. J Dent Res 85: 198-208, 2006.

14. Förstermann U, Schmidt HH, Pollock JS, Sheng H, Mitchell JA, Warner TD, Nakane M and Murad F: Isoforms of nitric oxide synthase. Characterization and purification from different cell types. Biochem Pharmacol 42: 1849-1857, 1991.

15. Menaka K, Ramesh A, Thomas B and Kumari NS: Estimation of nitric oxide as an inflammatory marker in periodontitis. J Indian Soc Periodontol 13: 75-78, 2009.

16. Moshage H, Kok B, Huizenga JR and Jansen P: Nitrite and nitrate determinations in plasma: A critical evaluation. Clin Chem 41: 892-896, 1995.

17. Lamster IB and Novak MJ: Host mediators in gingival crevicular fluid: Implications for the pathogenesis of periodontal disease. Crit Rev Oral Biol Med 3: 31-60, 1992.

18. Wadhwa D, Bey A, Hasija M, Moin S, Kumar A, Aman S and Sharma VK: Determination of levels of nitric oxide in smoker and nonsmoker patients with chronic periodontitis. J Periodontal Implant Sci 43: 215-220, 2013.

19. Gautam DK, Jindal V, Gupta SC, Tuli A, Kotwal B and Thakur R: Effect of cigarette smoking on the periodontal health status: A comparative, cross sectional study. J Indian Soc Periodontol 15: 383-387, 2011.

20. Reher VG, Zenóbio EG, Costa FO, Reher P and Soares RV: Nitric oxide levels in saliva increase with severity of chronic periodontitis. J Oral Sci 49: 271-276, 2007.

21. Sreedevi M, Ramesh A and Dwarakanath C: Periodontal status in smokers and nonsmokers: A clinical, microbiological, and histopathological study. Int J Dent 2012: 571590, 2012.

22. Hussain QA, McKay IJ, Gonzales-Marin C and Allaker RP: Regulation of adrenomedullin and nitric oxide production by periodontal bacteria. J Periodontal Res 50: 650-657, 2015.

23. Aurer A, Aleksić J, Ivić-Kardum M, Aurer J and Culo F: Nitric oxide synthesis is decreased in periodontitis. J Clin Periodontol 28: 565-568, 2001. 
24. Andrukhov O, Haririan H, Bertl K, Rausch WD, Bantleon HP, Moritz A and Rausch-Fan X: Nitric oxide production, systemic inflammation and lipid metabolism in periodontitis patients: Possible gender aspect. J Clin Periodontol 40: 916-923, 2013.

25. Förstermann U and Sessa WC: Nitric oxide synthases: Regulation and function. Eur Heart J 33: 829-837, 2012.

26. Chiossone L, Dumas PY, Vienne M and Vivier E: Natural killer cells and other innate lymphoid cells in cancer. Nat Rey Immunol 18: 671-688, 2018.
27. Bartold PM and Van Dyke TE: Periodontitis: A host-mediated disruption of microbial homeostasis. Unlearning learned concepts. Periodontol 2000 62: 203-217, 2013.

(i) $\Theta$ This work is licensed under a Creative Commons Attribution-NonCommercial-NoDerivatives 4.0 International (CC BY-NC-ND 4.0) License. 